\title{
A COMPLEXIDADE DO ATO DE LEITURA EM LÍNGUA INGLESA PARA ALUNOS INICIANTES
}

\author{
Lesliê Vieira MULICO - IFRJ/UERJ ${ }^{1}$
}

RESUMO: Políticas de letramento têm colocado o ato de leitura em posição de destaque para o ensino de línguas. Todavia, apesar de professores e alunos reconhecerem a importância da leitura para a cidadania, percebo que o hábito de ler não é prontamente adotado, especialmente quando se trata de leitura literária. Da mesma forma, no âmbito do ensino de leitura instrumental em língua inglesa para iniciantes, tal fato se repete mesmo estando o aprendiz consciente do papel-chave que a língua exerce na sociedade. Observando que a leitura literária em língua mãe e a de textos técnicos em língua inglesa suscitam rejeições semelhantes por parte do leitor aprendiz, hipotetizo que a leitura de textos ficcionais em língua mãe e não-ficcionais em língua inglesa são atos comparáveis, pois requerem a capacidade de abstrair metaforicamente as representações da linguagem. A fim de demonstrar a complexidade do processo, estabeleci um diálogo entre a teoria dos atos de leitura de textos ficcionais de Wolfgang Iser (1996) e o modelo da construção de sentido de Richard Kern (1996) para analisar as relações de contingência e algumas representações mentais que um determinado texto técnico em língua inglesa requer do leitor iniciante. Portanto, constatei que textos ficcionais e não-ficcionais requerem processos mentais e representações metafóricas semelhantes.

PALAVRAS-CHAVE: Leitura Instrumental; Leitor Iniciante; Abstração; Complexidade.

ABSTRACT: Literacy politics have put the act of reading in the spotlight in the scope of language teaching. Nonetheless, although teachers and learners recognize the importance of reading for citizenship, I notice that the reading habit is not readily adopted, especially when it comes to literary reading. Likewise, in the field of reading for specific purpose in English for beginners, said fact also occurs even if the learner is conscious of the key role the language plays in society. Upon observing that mother tongue literary reading and instrumental reading in English provoke similar rejections from the learner-reader, I hereby hypothesize that the act of reading fictional texts in the mother tongue and non-fictional ones in English are comparable acts, for they require the capacity to metaphorically abstract language representations. In order to demonstrate the complexity of this process, I have established a dialogue between Wolfgang Iser's reading act theory (1996) and Richard Kern's available designs and contextual layers in literacy (1996) so as to analyze the relationships of contingency and some mental representations that a given text in English requires form the reader. Hence, I have ascertained that both fictional and non-fictional texts require similar mental processing and metaphorical representations.

KEY-WORDS: Technical Reading; Beginner Reader; Abstraction; Complexity.

\section{INTRODUÇÃO}

\footnotetext{
1 Especialista em Linguística aplicada ao Ensino da Língua Inglesa pela Universidade do Estado do Rio de Janeiro (UERJ) e mestrando na área de Linguística pela mesma instituição. Professor de Inglês do Instituto Federal do Rio de Janeiro.
} 
O letramento se trata da habilidade ampla de lidar com outras pessoas como escritores e leitores $^{2}$ (BRANDT, 1990). É o resultado da ação de ensinar a ler e escrever dentro de um contexto em que a escrita e a leitura tenham sentido e façam parte da vida do aluno (SOARES, 2003). O letramento é a competência ampla do discurso que envolve a habilidade de interpretar e avaliar criticamente uma ampla variedade de textos orais e escritos (KERN, 2000). ${ }^{3}$ Essas três visões refletem uma concepção de letramento, seja ele em língua-mãe ou em segunda língua, que cada vez mais procura se afastar do simples ato de ler e escrever, e gradativamente se aproxima da habilidade do ser humano de atuar criticamente na sociedade. Observando essas definições, não é difícil perceber que elas visam à transformação do ser humano em protagonista de sua própria história por meio dos diversos textos orais, escritos, icônicos, etc., que circundam o ser humano em sua cultura. Com isso, a bandeira do letramento levantada por esses autores nos remete ao compromisso de fazer com que o aprendiz tome gosto pela leitura, fazendo dela uma necessidade humana (como respirar) para atuar de forma crítica na sociedade. Dessa forma, percebemos que o indivíduo letrado é munido de uma competência linguística capaz de agir criticamente na sociedade.

Se por um lado é fácil nos convencermos da necessidade de sermos leitores competentes dos textos que estão presentes na nossa cultura, é difícil fazer com que o aprendiz se torne um leitor habitual e de pensamento crítico, pois o ato de ler demanda, além de outras habilidades, a flexibilidade de pensamento, o que requer um esforço cognitivo que pode ser a barreira para o seu engajamento nessa atividade.

Tendo em vista essa complexidade da atividade leitora, será então possível teorizar sobre o esforço cognitivo que um aprendiz de língua inglesa iniciante deve investir uma vez em contato com textos na língua-alvo? Como o investimento na leitura de um texto em L2 é comparável ao de uma obra ficcional em L1? Estimulado por essas questões, e desafiado a letrar meus aprendizes em uma língua que não é a deles, procurarei entender melhor a complexidade dos atos de leitura de alunos iniciantes em contato com textos autênticos em inglês, e para tanto utilizarei o modelo da construção de sentido de Richard Kern (2000) em conjunto com a análise dos atos de apreensão do texto e da assimetria entre texto e leitor de Wolfgang Iser (1996). O esquema de Kern (2000) servirá para analisar um texto autêntico em inglês utilizado para o letramento de

\footnotetext{
${ }^{2}$ [literacy is] the broader ability to deal with other people as a writer or reader. (Brandt, 1990, apud Kern, 2000)

${ }^{3}$ literacy is broader discourse competence that involves the ability to interpret and critically evaluate a wide variety of written and spoken texts. (Kern, 2000)
} 
alunos iniciantes, e as categorizações de Iser (1996) ajudarão a entender a relação do leitor com esses textos.

A originalidade desse trabalho encontra-se na utilização das categorias de Iser (1996) para refletir sobre o processo de leitura de textos não ficcionais em língua-mãe, estabelecendo um diálogo com o Modelo da Construção de Sentido (KERN, 2000), idealizado para o letramento de aprendizes leitores em língua estrangeira. Após definir os aprendizes leitores, pretendo traçar um paralelo entre a leitura de texto não-ficcional em L2 e ficcional em L1, a fim de justificar o uso das categorizações de Iser (1996) para analisar os atos de apreensão do texto autêntico que utilizei na minha primeira aula de língua inglesa com esses leitores. Posteriormente, analisarei algumas implicações da competência leitora à luz de Iser (1996) e Kern (2000), conjecturando sobre alguns fatores que fazem o aprendiz agir na leitura, e fazendo um levantamento holístico das representações presentes no referido gênero textual, a fim de demonstrar a complexidade do ato de leitura de um texto em língua inglesa para esses aprendizes iniciantes, além de demonstrar como o ato de leitura de textos ficcionais em L1 é comparável com o de L2.

\section{IDENTIFICANDO O APRENDIZ INICIANTE}

O termo aprendiz iniciante pode ser entendido de várias formas. Os cursos livres de idiomas, ao chamarem de "básico" um grupo de períodos iniciais, também ajudam na construção dessa imprecisão. Ao mesmo tempo, hoje em dia é difícil imaginar um aluno adulto no Brasil que seja totalmente iniciante em língua inglesa, já que ela se faz presente em nossa cultura de diferentes formas, seja em nomes de lojas, seja em linguagem de computação, seja exposto em outdoors. Portanto, para definir aprendiz iniciante é preciso realizar uma reflexão mais cuidadosa, reconhecendo primeiramente que em nossa sociedade existem diferentes tipos de aprendizes iniciantes, o que vai depender do quanto ele experienciou a língua antes de estudá-la formalmente.

Reconhecendo essa realidade, passo a delimitar aprendiz iniciante com base no público para quem leciono no Instituto Federal de Educação, Ciência e Tecnologia do Rio de Janeiro, campus Pinheiral. Trata-se de alunos do primeiro período do curso de secretariado cujo contato com o ensino da língua inglesa se deu apenas no colégio em que estudam ou estudaram, onde o ensino é ou foi voltado majoritariamente, e de forma insipiente, aos aspectos gramaticais da língua. Parte desses alunos está cursando o 
ensino médio em uma outra instituição pública da região e alguns o concluíram há, no máximo, cinco anos. Como vivem em um município no interior do Rio de Janeiro, onde o acesso à cultura é mais limitado, a exposição à língua inglesa em suas comunidades é menor se comparada ao que acontece na capital.

No tocante à capacidade leitora, esse aprendiz consegue entender textos muito curtos e simples, uma frase por vez, identificando nomes familiares, palavras e frases básicas, relendo-as quando necessário, de acordo com a classificação do Quadro Europeu Comum de Referência para Línguas nível $\mathrm{A}^{4}$ (Common European Framework of Reference for Languages - CEFR). Alguns desses alunos iniciantes encontram-se abaixo desse nível, o que torna o ato de leitura em L2 mais desafiador. É importante ressaltar que o CEFR foi utilizado apenas para estabelecer o tipo de aluno iniciante referendado nesse trabalho, não implicando nenhuma interferência na prática pedagógica de letramento para esses alunos. Apesar de o CEFR orientar a elaboração de currículos, exames e livros didáticos na Europa, suas orientações são adequadas ao contexto brasileiro na medida em que estão sendo utilizados somente como ferramenta de generalização para situar o leitor desse artigo sobre o nível de proficiência em língua inglesa dos alunos observados. Assim sendo, talvez as elucubrações presentes nesse trabalho talvez não sirvam, por exemplo, para alunos iniciantes compreendidos um pouco acima da classificação do nível A1 do CEFR.

\section{ANALISANDO OS ATOS DE LEITURA DE TEXTOS TÉCNICOS COM CATEGORIAS PENSADAS PARA TEXTOS FICCIONAIS}

Muitos leitores provavelmente já devem ter passado pela experiência de ler um texto ficcional (ou não) e ficado com a impressão de que nada entenderam, ainda que escrito em sua língua-mãe. Tal fenômeno pode ser explicado por um viés sociológico e/ou levando-se em conta as dificuldades de processamento sintagmático e paradigmático do leitor. Sendo assim, de forma geral o texto parece exigir certo conhecimento de mundo, flexibilidade de pensamento e sensibilidade do leitor para que seja apreendido.

Procurando entender melhor essa relação entre o leitor e o texto, Wolfgang Iser (1996) explica o processo de leitura em L1 por meio da descrição dos atos de apreensão

\footnotetext{
${ }^{4}$ Can understand very short, simple texts a single phrase at a time, picking up familiar names, words and basic phrases and rereading as required. (CEFR, p. 69)
} 
do texto e da assimetria de texto e leitor. O autor organiza os atos de apreensão em "momentos paradigmáticos" (p. 13), apropriando-se inicialmente de conceitos psicolinguísticos obtidos a partir de resultados empíricos, ao passo que analisa a assimetria entre texto e leitor segundo as condições de interação propostas pela psicologia social, referentes aos tipos de contingência que podem emergir das interações humanas.

Sobre os atos de apreensão do texto, uma noção que Iser (1996) nos mostra é a de que a decodificação de uma frase não ocorre no nível da palavra, mas no nível dos grupos lexicais correspondentes às unidades sintáticas de uma sentença. Segundo o autor, como essas unidades marcam uma dimensão minimalizada da percepção do texto e como as operações da frase em textos ficcionais não se cumprem na denotação de objetos empiricamente dados, o interesse se dirige ao leitor quando ele entrecruza correlatos para alcançar a plenitude semântica. Iser mostra que os indicadores semânticos de uma enunciação individual suscitam no leitor memórias que se transformam em pano de fundo para uma expectativa do que virá. Com base no pensamento de Husserl (1966), Iser (1996) chama essa expectativa de protensão, e essas memórias de retenção. Com isso, o autor afirma que há uma dialética de retenção e protensão representada em cada momento de leitura.

Ao mesmo tempo, Iser enfatiza que, no plano da enunciação, não existe uma interação perfeita entre retenção e protensão. Por exemplo, quando a frase seguinte não tem ligação perceptível com a frase que o leitor acabou de pensar, ocorre um hiato (INGARDEN, 1968), ou seja, a quebra do fluxo de pensamento por meio da falha no fluxo das enunciações. Todavia, Iser (1996) ratifica que a interrupção das conexões esperadas é "paradigmática para os diferentes processos de focalização que acontecem durante a leitura de textos ficcionais" (p.19). Com isso, Iser (1996) demonstra que o leitor estabelece seu lugar quando se move no interior do texto para combinar as diferentes perspectivas textuais.

A movimentação do leitor provoca a assimetria nas condições de interação, as quais Iser analisa segundo a teoria da interação proposta pela psicologia social de Edward E. Jones e Harold B. Gerald (1967). Tal teoria estabelece quatro categorias de tipos de contingência que emergem nas interações humanas. A pseudocontingência ocorre quando os parceiros interacionais têm intimidade com o plano de conduta do outro, podendo assim prever as réplicas e suas consequências, como a falas ensaiadas em uma peça de teatro; a contingência assimétrica ocorre quando um dos parceiros 
desiste de seu próprio plano de conduta para seguir o do outro, adaptando-se a ele; a contingência reativa, ao contrário da anterior, inviabiliza qualquer tentativa dos parceiros de atuarem segundo seus próprios planos de conduta; e a contingência mútua domina a tentativa de reação para impor um determinado plano de conduta, o que pode resultar ou no sucesso da interação ou em hostilidade.

Estabelecidos os diferentes tipos de contingências, o autor ratifica que elas nascem da interação em si, já que diferentes planos de conduta entram em jogo somente quando ela se inicia. No que se refere ao ato de leitura, podemos afirmar que texto e leitor se tornam parceiros interacionais, porém, Iser (1996) observa que é o leitor quem deve adaptar seu plano de conduta a fim de interagir efetivamente com o texto, já que seu caráter invariável provoca uma multiplicidade de representações no leitor. Talvez seja essa incapacidade de adaptar-se a novos contextos comunicativos é o que faz com que o indivíduo não-letrado esteja mais propenso a passar pela experiência do analfabetismo funcional mencionado no início dessa seção. Com base nessas considerações, podemos assim sugerir que a contingência assimétrica tem papel de destaque na relação entre texto e leitor, pois é necessário que ele abdique de seu plano de conduta para poder estabelecer um diálogo com o texto, além do fato de que o leitor é o único parceiro capaz de flexibilizar seu plano de conduta nessa interação.

De forma geral, Iser (1996) nos mostra que o leitor passa por processos de retenção e protensão no nível correlacional, e de hiato no nível da enunciação, a fim de apreender o texto ficcional. Além disso, o autor demonstra que o texto e o leitor são participantes discursivos que interagem de forma contingencial assimétrica, o que requer do leitor a flexibilidade no seu plano de conduta para que o diálogo seja possível.

Processos similares parecem acontecer quando os participantes discursivos são o texto técnico em inglês (não ficcional) e o aprendiz iniciante. No que tange às condições de interação, o aprendiz iniciante também deve abdicar do seu plano de conduta para compreender tanto os aspectos ideológicos e sentenciais, quanto o léxico per se, pois a sua língua-mãe (L1) passa a exercer um papel referencial nessa interação. Tal fato demanda do aprendiz uma alta tolerância à ambiguidade, pois nem sempre a L1 será eficaz no auxílio à decodificação como, por exemplo, quando se trata dos falsos cognatos. Quanto aos atos de apreensão do texto para o referido leitor, sentenças e palavras tornam-se hiatos a serem preenchidos pelo seu conhecimento de mundo, pelos elementos suprasegmentais que o texto oferece, pelo contexto comunicativo, pelas semelhanças linguísticas entre L1 e L2 ou por fatores de outras naturezas. Com isso, o 
aprendiz iniciante de língua inglesa parece passar por processos equivalentes de protensão e retenção como o indivíduo lendo um texto ficcional em sua própria língua, já que ambos precisam reter novas formas e sentidos na memória para anteciparem a informação que virá. Portanto, é possível que as representações presentes em um texto ficcional suscitem no leitor processos dialógicos similares aos que ocorrem com o aprendiz iniciante de L2 frente a um texto em inglês. Sendo assim, seria então possível comparar o ato de leitura de textos ficcionais em L1 com o ato de leitura de textos nãoficcionais em L2, já que envolvem abstrações metafóricas equivalentes.

\section{MODELO DE CONSTRUÇÃO DE SENTIDOS}

Se por um lado Iser (1996) demonstra que a interação entre texto e leitor é contingencial, Kern (2000), por sua vez, demonstra que essa contingência ocorre em diversos níveis da construção do sentido. No centro desse modelo encontramos o texto fazendo um movimento cíclico e iterativo com os elementos estruturais e organizadores da leitura e escrita, tais como o vocabulário, a gramática, os gêneros, o estilo, o sistema de escrita, assim como os elementos necessários para o processamento cognitivo, i.e., o conhecimento procedural e o declarativo. $\mathrm{O}$ autor afirma que, a partir do momento em que o leitor entra em contato com o texto, esses elementos iniciais evoluem para dimensões comunicativas e socioculturais, já que "ler e escrever não se tratam de construtos singulares e unitários, mas de construtos culturais, contextuais e dependentes da tarefa"5 (KERN, 2000). À luz de Iser (1996) e Kern (2000), podemos então argumentar que tal movimento evolutivo de dentro para fora ocorre na medida em que o leitor utiliza seu próprio conhecimento de mundo para dialogar com o texto.

Outro diálogo possível entre Kern (2000) e Iser (1996) que podemos destacar está na noção de processamento da frase. Ambos os autores argumentam que nossa compreensão vai para além da decodificação de grupos de palavras e, com isso, construímos significados baseados no reconhecimento das relações particulares entre as palavras do texto. Da mesma forma, estabelecemos relações entre o texto que estamos lendo e outros textos anteriormente lidos, o que Iser (1996) classifica como protensão e retenção, como aprofundado na seção anterior. Já Kern (2000) se espraia para questões mais voltadas para a formação leitora do aprendiz.

Kern (2000) aponta os seguintes fatores como princípios do letramento: $a$ interpretação, a colaboração, as convenções culturais, o conhecimento de diferentes

\footnotetext{
${ }^{5}$ reading and writing are not singular, unitary constructs, but rather culture-, context-, and task-dependent constructs. (Kern, 2000)
} 
culturas, a solução de problemas, a reflexão e autocrítica, e o uso da linguagem de forma integrada no discurso. A partir desses princípios podemos afirmar que a leitura do aprendiz letrado extrapola os fatos e informações dadas (interpretação), que o leitor é capaz de fazer implicações e negociar o significado (colaboração), e que ele consegue depreender as normas linguísticas compartilhadas e seus respectivos fins (convenções culturais). Para tanto, o contato recursivo com a leitura de diversos gêneros pode expandir a visão de que o mundo não somente gira em torno de sua própria cultura (conhecimento cultural), levando-o a agir nele criticamente de forma reflexiva. Dessa forma, linguagem e discurso tornam-se entes indissociáveis, fazendo com que leitor se torne um analista do discurso.

Como vimos, a aplicação de tais princípios faz com que o aluno ultrapasse o limite dos fatos e das informações dadas, já que envolve implicações e negociação do significado. Dentro de um contexto de aprendizagem como esse, o aprendiz é incentivado a pensar nos aspectos sociais, cognitivos e culturais que necessariamente remetem aos aspectos linguísticos do texto. Dentro desse escopo, Kern (2000) propõe uma organização dos esquemas disponíveis em níveis contextuais envolvidos no letramento, a fim de estabelecer critérios para práticas que favoreçam uma aprendizagem de L2 que dê conta não somente dos fatores linguísticos e cognitivos, mas inclua elementos socioculturais, como podemos observar no esquema abaixo.

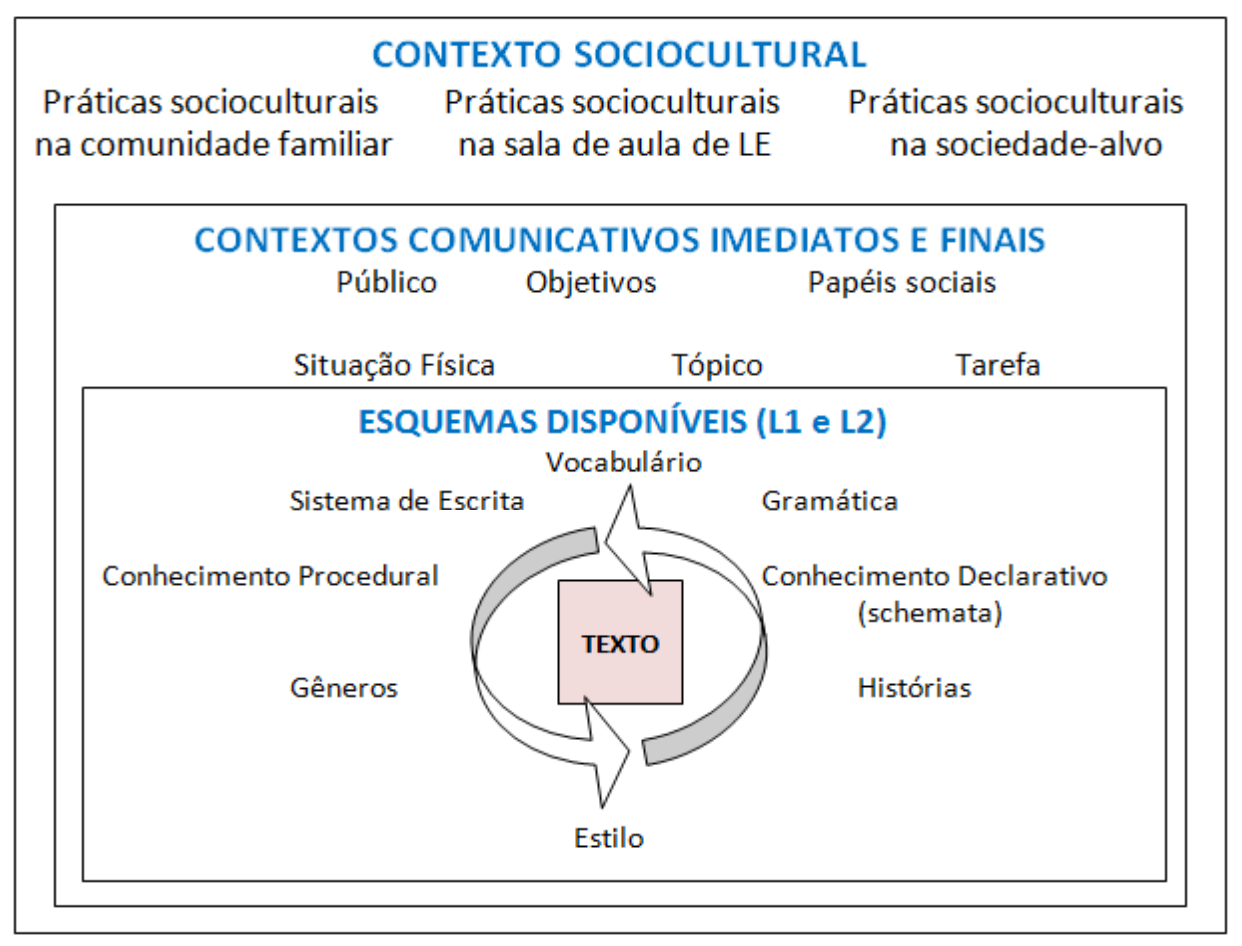

Figura 1: Modelo da Construção de Sentido (KERN, 1996) 
Observando o Modelo da Construção de Sentido de Richard Kern (2000), é possível notar que ele abrange desde esquemas linguísticos imediatos até elementos extralinguísticos do texto, já que dele também emergem construtos culturais, contextuais e atitudinais. Os esquemas linguísticos imediatos encontram-se no centro do modelo, já que se trata do nível linguístico inicial que o leitor precisa dar conta. Entretanto, dominar apenas os níveis iniciais de letramento não é suficiente para a aquisição de competência leitora. É preciso que entrem em jogo os contextos comunicativos (segunda dimensão). O tipo de atividade para letramento influencia o foco que o leitor dá no sentido em detrimento da forma, ou vice-versa. Com isso, podemos depreender que o propósito de leitura norteia as ações do leitor, assim como o tópico influencia a maneira com a qual ele vai utilizar seu conhecimento de mundo durante a atividade. Com relação a esses dois níveis, Kern (2000) ainda reitera que o nível mais geral, o do contexto sociocultural, influencia os outros dois, já que se refere ao contexto em que o aprendiz leitor aprendeu a segmentar o mundo.

Dessa forma, podemos argumentar que o modelo de Kern (2000), em consonância com as categorias de Iser (1996), serve de relevante embasamento teórico para demonstrar que, sendo elementos comparáveis, a leitura de um texto em L2 para o aprendiz iniciante pode ser tão complexa quanto à leitura de texto ficcional em L1. A partir dos pressupostos teóricos elencados, passemos a analisar um dos textos utilizados no letramento de alunos iniciantes de língua inglesa.

\section{O TEXTO E OS ATOS DE LEITURA EM CÂMERA LENTA}

O texto selecionado para a presente análise se trata de um site de divulgação de um curso à distância para assistentes administrativos. Como dito anteriormente, o contexto profissional é o que orienta a seleção de textos para as atividades de ensino de língua inglesa, já que se trata de formação profissional.

Portanto, analisaremos o texto abaixo sob o ponto de vista da relação com o leitor, de acordo com a teoria de Iser (1996), e sob a perspectiva do letramento por meio do modelo de Kern (2000). As teorizações de Iser e Kern são cooperativas na medida em que levam a entender a natureza plural do texto e do ato de ler. Se por um lado Iser procura desvelar processos de embate individual do leitor com o texto, por outro Kern concebe a leitura de forma holística, organizada em níveis de maior ou menor 
abrangência, desde elementos linguísticos até contextos socioculturais que exercem influência entre si.

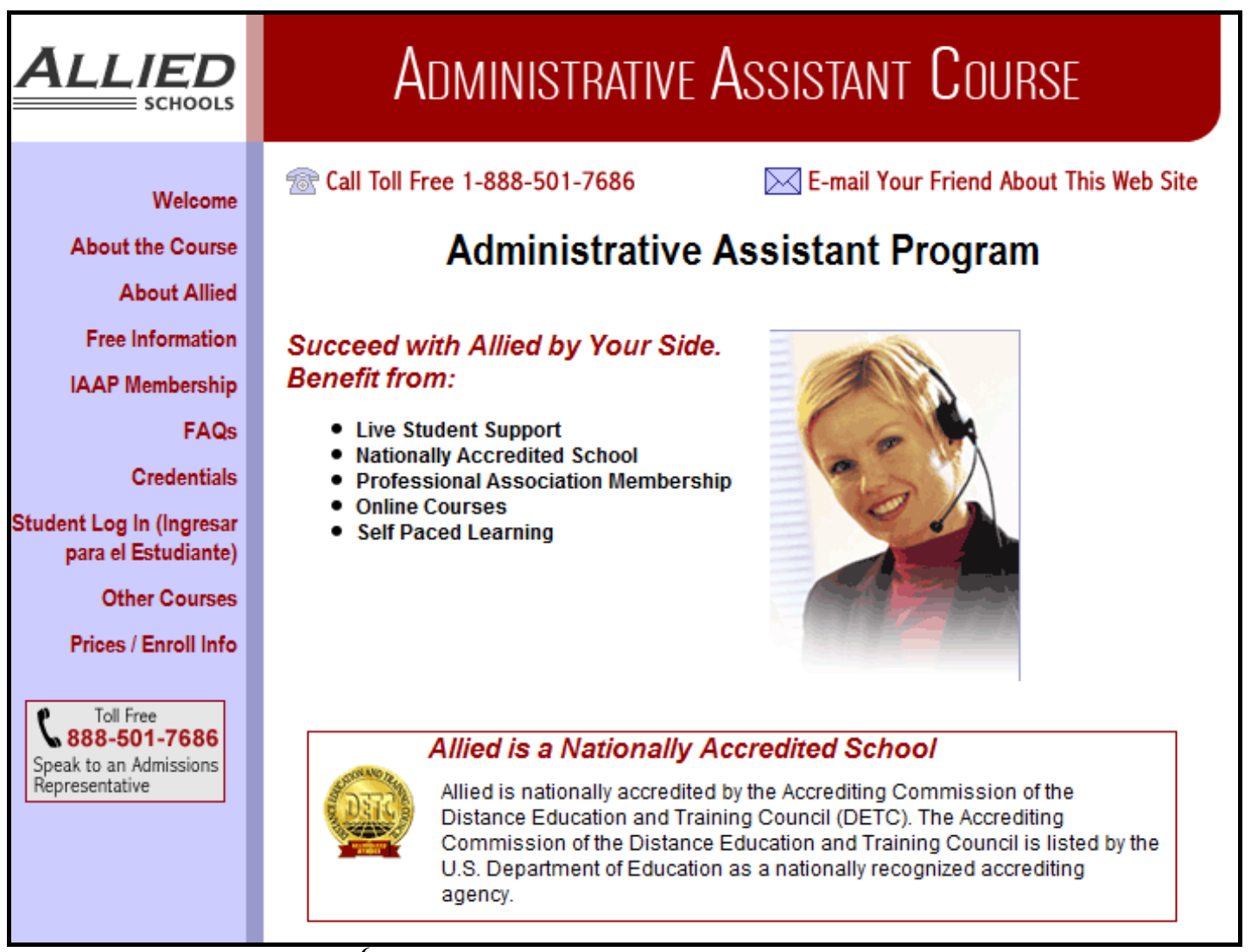

Figura 2: site de divulgação ${ }^{6}$

Como podemos observar, a proposta desse site é de divulgar um curso à distância para formar assistentes administrativos. Trata-se de um texto autêntico, já que não foi concebido para o ensino da língua inglesa no contexto discursivo em que ocorre. O interesse de se aproveitar um texto como esse para ensinar inglês ao grupo de iniciantes aqui destacado foi o fato de que além de seu contexto estar dentro do escopo temático de sua futura atividade profissional, esse fragmento possui elementos facilitadores do processamento linguístico, tais como o grande número de cognatos, a disposição gráfica das informações e a presença de elementos semióticos que fazem parte da cultura dos alunos, tais como os ícones e a foto. O olhar da secretária se dirige ao leitor convidando-o ao diálogo, seu sorriso convincente parece transmitir credibilidade, e sua cabeça está ligeiramente inclinada, o que remete à empatia de quem interage com o público. Essas são algumas das práticas que secretárias no mundo real precisam exercitar para atender bem e convencer. Além disso, o uso do fone de ouvido, e não do telefone, aponta para uma prática do politicamente correto, alinhada com a

6 (Disponível em http://www.secretarialcourses.com/. Acesso em 15/01/11) 
contemporaneidade. No que se refere à medalha, ela também nos lembra de todo o sistema de ISO 9000 e liderança através da qualidade que rege o funcionamento do mundo empresarial / industrial nesse momento sócio-histórico.

As condições de assimetria que o aluno iniciante experiencia como leitor envolvem níveis de compreensão em esferas macro e microcósmicas. Quanto ao processamento do novo léxico, o referido texto requer que o aprendiz adapte o sistema linguístico do português do qual dispõe para desempenhar um trabalho interlinguístico correlacional eficiente a fim de que a coconstrução do sentido no texto seja possível. O hiato ocorre quando o conhecimento de L1 do aprendiz não é suficiente para compreender determinados trechos em L2, podendo resultar em atitudes como o abandono total do texto ou de uma frase inteira, o abandono parcial do texto ou de uma palavra da frase em prol do fluxo de leitura, ou o esforço para deduzir o sentido da palavra dentro da frase. Isso demonstra a influência do plano de conduta do aprendiz no processo de leitura, cabendo ao professor dar subsídios para esse aluno preencher esses hiatos e então se tornar um leitor competente. Portanto, podemos notar a complexidade do ato de leitura quando observamos que: a) a contingência assimétrica de interação desafia o aprendiz a dialogar com o texto desde o nível formal da palavra até níveis que extrapolam o ato da decodificação; b) os hiatos que emergem da negociação de sentido apontam caminhos a serem percorridos para a aquisição da linguagem; c) o professor se alia ao aprendiz como participante nessa negociação; d) a mediação do professor é necessária para que o aprendiz consiga adaptar seu plano de conduta para ser capaz de preencher esses hiatos.

Tendo em mente tal complexidade, observamos que Kern (2000), ao pensar em letramento, vislumbra o texto dentre categorias que vão para além do nível linguístico e, pois, servem de parâmetros para auxiliar no entendimento de como a leitura de um texto em língua inglesa provavelmente se configura para os alunos iniciantes aqui delineados. Como podemos observar na tabela abaixo ${ }^{7}$, além dos aspectos linguísticos inseridos no nível esquemático, os aspectos socioculturais e comunicativos extrapolam as linhas do texto, situando-o em níveis de leitura mais amplos. Dessa forma, esta tabela procura analisar o texto da Figura 2 a partir das categorias do modelo de Kern (2000), na Figura 1, apresentando descrições e implicações do texto para o leitor iniciante de língua

\footnotetext{
${ }^{7}$ Agradeço a Professora Dra. Tânia Mara Gastão Saliés por ter me auxiliado nessa análise.
} 
inglesa, e consequentemente para a complexidade do ato de leitura. Sendo assim, a tabela está organizada do nível geral para o específico, tal como Kern (2000) apresenta.

\begin{tabular}{|c|c|}
\hline \multicolumn{2}{|c|}{ CONTEXTO SOCIOCULTURAL } \\
\hline $\begin{array}{l}\text { Práticas } \\
\text { socioculturais } \\
\text { na sociedade- } \\
\text { alvo }\end{array}$ & $\begin{array}{l}\text { - Divulga um curso para assistente administrativo; } \\
\text { - Indica o telefonema gratuito como alternativa de interação; } \\
\text { - Provê um link para que o leitor possa divulgar o curso a seus amigos, estimulando } \\
\text { o marketing boca-a-boca; } \\
\text { - Subjaz questões culturais: contexto cultural presente na foto estabelecendo a } \\
\text { aparência da mulher participante desse nicho social; o número de telefone } \\
\text { gratuito iniciado por 1-888 e não por 0800 e a instituição que acredita o curso é } \\
\text { diferente da presente em nossa própria cultura. }\end{array}$ \\
\hline $\begin{array}{l}\text { Práticas } \\
\text { socioculturais } \\
\text { em sala de } \\
\text { aula }\end{array}$ & $\begin{array}{l}\text { - Propõe que o aprendiz decida se faria o curso ou não e explique seus motivos } \\
\text { - Apropria de estratégias de leitura, como abordagem top-down para reconhecer o } \\
\text { contexto e seus componentes, bottom-up para decodificação do código e dedução } \\
\text { de palavras e trechos; skimming e scanning para atender a objetivos diferentes; } \\
\text { - Permite ao aluno utilizar a sua própria língua como trampolim para decodificar as } \\
\text { informações do texto em língua inglesa, mesmo sem ensino prévio de } \\
\text { vocabulário, através dos cognatos e ícones presentes no site e do reconhecimento } \\
\text { de práticas socioculturais desse contexto de trabalho; } \\
\text { Leva os cognatos a ajudarem o aluno a reconhecer elementos ortográficos } \\
\text { semelhantes à sua própria língua e, com isso, começar a perceber as } \\
\text { especificidades entre as línguas. }\end{array}$ \\
\hline $\begin{array}{l}\text { Práticas } \\
\text { socioculturais } \\
\text { na } \\
\text { comunidade } \\
\text { familiar }\end{array}$ & $\begin{array}{l}\text { - O curso divulgado se trata de um meio de ascensão social pela formação } \\
\text { profissional continuada } \\
\text { O curso oferece ferramentas para que essa ascensão ocorra, tais como: apoio ao } \\
\text { aluno em tempo real, escola com acreditação nacional e membro de associação } \\
\text { profissional, cursos à distância, aprendizagem de acordo com o ritmo do aluno. }\end{array}$ \\
\hline \multicolumn{2}{|c|}{ CONTEXTOS COMUNICATIVOS IMEDIATOS E FINAIS } \\
\hline Público & $\begin{array}{l}\text { - } \text { Profissionais de administração; } \\
\text { - } \quad \text { Alunos de cursos técnicos; } \\
\text { - Usuários de internet; } \\
\text { - Alunos com motivação intrínseca e com certo grau de auto-organização e } \\
\text { disciplina. }\end{array}$ \\
\hline Objetivos & $\begin{array}{l}\text { - Passar credibilidade ao leitor; } \\
\text { - } \quad \text { Mostrar ao leitor como ele poderá se beneficiar dos serviços oferecidos; } \\
\text { - } \quad \text { Divulgar o curso. }\end{array}$ \\
\hline Papéis sociais & $\begin{array}{l}\text { - O curso é o vendedor, detentor do poder de formação de quem se inscrever. É, } \\
\text { ou talvez seja, a porta de entrada para o mercado de trabalho e para o sucesso } \\
\text { profissional; } \\
\text { - O leitor é consumidor potencial, detentor do poder de compra, mas ao mesmo } \\
\text { tempo é quem depende da formação para ingressar no mercado de trabalho, ou } \\
\text { de ter perspectivas de maiores salários. }\end{array}$ \\
\hline $\begin{array}{l}\text { Situação física } \\
\text { (cenário) }\end{array}$ & $\begin{array}{l}\text { Em situação real, o leitor estaria navegando na rede, provavelmente à procura } \\
\text { de formação complementar dentro de sua área. Sem a mediação do professor de } \\
\text { línguas, isso implicaria uma leitura rápida, focada no sentido em detrimento da } \\
\text { forma, o que provavelmente garantiria uma leitura superficial do texto em } \\
\text { busca apenas de informações-chave, como telefone e outros links. No contexto } \\
\text { pedagógico mediado pelo professor, os alunos tiveram a oportunidade de } \\
\text { trabalhar tanto os aspectos formais da L2 em contraste com a L1, quanto os } \\
\text { aspectos comunicativos do referido texto. }\end{array}$ \\
\hline Tópico & - $\quad$ Propaganda de um curso para assistente administrativo \\
\hline Tarefa & $\begin{array}{l}\text { - } \quad \text { Ler e decodificar; } \\
\text { - } \quad \text { Ler e interpretar; } \\
\text { - } \quad \text { Ler e prosseguir com a inscrição; }\end{array}$ \\
\hline
\end{tabular}




\begin{tabular}{|c|c|}
\hline & $\begin{array}{ll}\text { - } & \text { Ler e divulgar para um amigo; } \\
\text { - } & \text { Decidir sobre sua ação a partir da leitura. }\end{array}$ \\
\hline \multicolumn{2}{|c|}{ ESQUEMAS DISPONÍVEIS (L1 e L2) } \\
\hline Histórias & (não avaliado) \\
\hline Estilo & $\begin{array}{l}\text { - Denotativo e factual; } \\
\text { - } \quad \text { Contraste de cores para o nome do curso, colocado ao topo do texto; } \\
\text { - Uso da cor vermelho-escura como plano de fundo e nas palavras que são links } \\
\text { importantes e para emoldurar números de telefones e acreditação; } \\
\text { - Uso de pontos para enumerar os benefícios; } \\
\text { - Informações que respaldam o curso e organizam as informações do site à } \\
\text { esquerda e em vermelho. }\end{array}$ \\
\hline Gêneros & - $\quad$ Site de divulgação de curso \\
\hline $\begin{array}{l}\text { Conhecimento } \\
\text { procedural }\end{array}$ & $\begin{array}{l}\text { - Alunos deverão interagir automaticamente com propagandas semelhantes, } \\
\text { entendendo o propósito comunicativo e efeitos a partir da linguagem e rituais } \\
\text { interacionais do contexto; } \\
\text { - Os alunos deverão reconhecer automaticamente esses elementos e usá-los em } \\
\text { contextos semelhante. }\end{array}$ \\
\hline $\begin{array}{l}\text { Sistema de } \\
\text { escrita }\end{array}$ & (não avaliado) \\
\hline Vocabulário & $\begin{array}{ll}\text { - } & \text { Cognatos; } \\
\text { - } & \text { Sintagmas nominais; } \\
\text { - } & \text { Verbos no imperativo; } \\
\text { - } & \text { Adjetivos }\end{array}$ \\
\hline Gramática & $\begin{array}{l}\text { - } \quad \text { Sintagmas nominais; } \\
\text { - Verbos no imperativo; } \\
\text { - Frases SVO com estrutura sintática que se utiliza de verbos de ligação, } \\
\text { adjetivos apassivados e presente passivo }\end{array}$ \\
\hline $\begin{array}{l}\text { Conhecimento } \\
\text { declarativo } \\
\text { (schemata) }\end{array}$ & $\begin{array}{l}\text { - O contexto do curso técnico de secretariado no qual participa ajuda o aluno a } \\
\text { investir imaginativamente na decodificação das informações presentes no site; } \\
\text { - Conhecimento explícito e focado na forma da propaganda como gênero textual } \\
\text { assim como dos elementos que o compõem; por exemplo, o uso do imperativo; } \\
\text { prática focada na forma para cognatos, sintagmas nominais e adjetivos; } \\
\text { aspectos da multimodalidade. Prática explícita com os elementos do contexto. }\end{array}$ \\
\hline
\end{tabular}

Tabela 1: Análise do site de divulgação segundo o modelo da construção de sentido (KERN, 2000)

Com a leitura da tabela acima, podemos visualizar os diversos elementos que estão em jogo na leitura de um texto em inglês para iniciantes, o que confirma a sua complexidade. Na descrição do contexto sociocultural, observamos que as práticas socioculturais que emergem do texto se assemelham às da realidade social dos alunos em questão, pois envolve um texto digital que faz emergir construtos comuns à sociedade alvo e aos alunos pertencentes à sociedade leitora, como por exemplo, o uso do apelo visual e recursos característicos do gênero digital, tais como o hipertexto, sem contar o fato de que se trata de um texto publicitário referente à área de interesse profissional do aluno leitor. Devido a essa aproximação, é provável que o leitor aprendiz se sinta compelido a investir na decodificação do texto, e com a mediação promovida pelo professor de línguas, tal ato de leitura se inicia a partir da descrição dos aspectos gerais do texto para os aspectos mais específicos (processamento top-down). Posteriormente, o aprendiz necessitará de utilizar seu conhecimento de mundo e L1 para 
decodificar o texto em si, sendo que haverá momentos em que isso não será suficiente, forçando o aprendiz a mudar de estratégia, como por exemplo, tentando deduzir a palavra na frase dentro do contexto (processamento bottom-up). É importante destacar o necessário entrecruzamento de linguagens, culturas e conhecimento de mundo para que a leitura desse texto seja bem sucedida no nível do contexto sociocultural. Dessa forma, o contexto sociocultural do leitor e do texto influencia na maneira como a leitura se procederá, assim como na mediação do professor, e isso faz com que esse contexto influencie tanto o contexto comunicativo quanto os níveis de leitura iniciais.

No nível dos contextos comunicativos, a complexidade do ato de leitura ocorre no nível da inter-relação entre os fatores que subjazem a compreensão do discurso, i.e., os papéis sociais designados para cada participante e o reconhecimento dos objetivos do texto, e a ação socialmente aceita que o aprendiz decide tomar a partir da leitura. Em outras palavras, o leitor não é apenas o receptor passivo de informações, mas sim participante do discurso na interação com o texto. Com isso, podemos agora perceber mais concretamente os limites entre o ensinar a decodificar e o letrar para agir.

Finalmente, no que tange aos esquemas disponíveis, categorias mais imediatas ao texto, a complexidade do ato de leitura envolve a compreensão dos elementos linguísticos aliada à capacidade de abstração do conteúdo a partir da interface entre L2 e L1. Como o aprendiz leitor se trata de aluno iniciante, a sua própria língua torna-se uma das poucas ferramentas que ele dispõe. Dessa forma, assim como a leitura ficcional em L1 requer do leitor uma capacidade de metaforização, o aluno iniciante em contato com o texto em língua inglesa precisa relativizar a nova grafia e a nova organização de ideias à luz dos elementos presentes em sua própria língua. Em última análise, podemos descrever que no processo de formação do leitor bilíngue, espera-se que ele adquira uma espécie de capacidade de metaforização interlinguística, e isso faz com que possamos estabelecer essa relação entre a leitura de textos ficcionais em L1 e não ficcionais em L2.

As análises dos atos de leitura e do texto aqui presentes corroboram com o fato de que a relação entre o texto e o leitor se trata de um jogo comunicativo complexo iniciado a partir do momento em que a interação entre eles se estabelece. Tal complexidade se inicia na decodificação do léxico e extrapola para representações mais amplas, fazendo do aprendiz um participante na coconstrução do sentido.

\section{CONCLUSÃO}


De acordo com o que foi exposto, notamos que processos semelhantes ocorrem tanto na leitura de textos ficcionais em L1 quanto em textos não ficcionais em L2 por aprendizes iniciantes, tornando possível a utilização da teoria de Iser (1996) para compreender melhor como esses processos podem ocorrer. Foi também possível observar como o texto para o letramento em L2 se articula em níveis que vão do sistemático até o sociocultural, segundo o modelo de Kern (2000). Com isso, tanto a teoria de Iser (1996) quanto o modelo de Kern (2000) permitem reiterar que a leitura de textos em inglês por alunos iniciantes se trata de um ato complexo, já que a relação entre esses pares interativos é de contingência assimétrica, exigindo que o leitor adapte seu plano de conduta para dialogar com o texto e preencher os hiatos que emergem ao longo do processo de leitura.

\section{REFERÊNCIAS BIBLIOGRÁFICAS}

BRANDT, D. Literacy as involvement: the acts of writers, readers and texts. Carbondale, IL: Southern Illinois University Press, 1990.

COMMON EUROPEAN FRAMEWORK. Oral assessment criteria grid (CEFR Table 3). disponível em <http://www.coe.int/T/DG4/Portfolio/documents/grid.pdf. $>$ Acesso em: 15 maio. 2010.

HUSSERL, E. Zur phänomenologie des inneren zeitbewusstsein. Haag: Martinus Nijhoff. Husserliana, 1966. Vol. 10.

INGARDEN, R. Vom erkennen des literarischen kunstwerks. Tübingen. Max Niemeyer Verlag, 1968.

ISER, W. Os atos de apreensão do texto. In: . $O$ ato de leitura. Rio de Janeiro: Editora 34, 1996. Vol. 2, p. 9-27.

ISER, W. A assimetria de texto e leitor. In: $O$ ato de leitura. Rio de Janeiro: Editora 34, 1996. Vol. 2, p. 97-108.

JONES, E.E. \& HARRIS, V. A. The attribution of attitudes. Journal of Experimental Social Psychology, n. 3, p. 1-24, 1967.

KERN, R. Communication, literacy and language teaching. In: Literacy and language teaching. Oxford: OUP, 2000. Cap. 2, p. 30-56.

SOARES, Magda. Letramento: um tema em três gêneros. Belo Horizonte: Autêntica, 2003. 